\title{
Editorial
}

\section{Perspectivas sombrias para la izquierda salvadoreña}

La izquierda salvadoreña no se agota en el FMLN, pero este partido es una de sus expresiones más importantes. Desde criterios puramente políticos, el FMLN ha sido, hasta abora, el partido que ha aglutinado las ansias de quienes, en El Salvador, no están dispuestos a plegarse a los designios de la derecha y ARENA. Ha babido otras agrupaciones politicas que también se han querido situar a la izquierda del espectro político, pero ban fracasado en el intento de convertirse en proyectos políticos viables.

Las razones que explican ese fracaso son varias: sus líderes no pudieron demarcarse de su pasada trayectoria vinculada, directa o indirectamente, al FMLN; las propuestas que abanderaron no fueron convincentes para los sectores sociales a los que iban dirigidas; los nuevos proyectos politicos fueron vistos como una traición a los ideales por los que antes se luchó; fue difícil ver en esas propuestas algo más que un afán meramente electorero... A estos factores conviene añadir dos, de enorme relevancia: a) por lo general, las nuevas formaciones de izquierda no sólo surgieron del seno del $F M L N$, sino que se enfrascaron en una fuerte disputa con ese partido - disputa iniciada en los momentos de la ruptura, pero continuada con posterioridad a ella-, desgastando sus posibilidades 
de emerger y consolidarse como proyectos novedosos de izquierda; b) asimismo, en el marco de esa disputa, la estrategia que privilegiaron, para sobrevivir electoralmente, fue la de arrebatar votos al FMLN, lo cual condicionó, desde un principio, sus posibilidades reales de convertirse en protagonistas del sistema politico. Fue una ingenuidad haber pensado que los votantes del FMLN eran unos votantes sin convicciones firmes, dispuestos a abandonar su partido por otro, cuyos dirigentes creian que lo unico que bastaba para atraerlos era proclamarse como una nueva izquierda.

En suma, la principal debilidad de las formaciones de izquierda que han irrumpido en el escenario político de la postguerra radica en que han intentado, como estrategia básica de sobrevivencia politico-electoral, arrebatarle votos al FMLN. No ban buscado ser una opción más de izquierda, dispuestas a ocupar, junto con otras, una espacio político que ciertamente puede ser más amplio en términos de partidos y de electores, sino que pretendieron desplazar al FMLN, es decir, ocupar su lugar, quedándose con sus votos $y$ con su cuota de poder. Como resultado de ello, sobrevino el fracaso político. $Y$, a tono con estas experiencias de fracaso, se impuso la tesis de que en El Salvador no habia más espacio en la izquierda para otro partido que no fuera el FMLN y que cualquier formación política de izquierda — desmembrada o no del FMLN- estaba condenada a desaparecer. Esta visión de las cosas ha sido la mejor arma de quienes, al final, se quedaron regentando los destinos del partido de izquierda. Ella les ha servido no sólo para mirar con sorna el destino de los disidentes, sino para legitimar su propia ascendencia dentro del FMLN. Su entronización en la "verdadera" $y$ unica izquierda se veía avalada por el fracaso de quienes osaron desafiar -no importa por cuáles razones- su autoridad revolucionaria.

Esa misma visión ha sido la que ha servido a muchos - dentro $y$ fuera del FMLN - para interpretar la situación y perspectivas del Frente Democrático Revolucionario (FDR), el nuevo proyecto de izquierda que ba emergido de la más reciente crisis del FMLN. Para quienes no ven con buenos ojos su surgimiento del FDR, este partido en proceso de legalización no tendrá un futuro distinto al del PD y al del Movimiento Renovador. $Y$ no será de otro modo - dicen-porque se trata de un partido que, además de contar en 
sus filas con figuras que ban traicionado la causa revolucionaria $y$ que se han vendido a la derecha neoliberal, pretende -al igual que bicieron socialdemócratas y renovadores- bacerse de una parte del caudal electoral del FMLN, lo cual ba mostrado ser un propósito condenado al fracaso. No babria, este sentido, diferencias importantes entre el PD, el Movimiento Renovador y el FDR. Todos serían expresión de un mismo esfuerzo -propiciado por la derecha y facilitado por las ambiciones de los disidentes-encaminado a debilitar al FMLN. No obstante, al igual que fracasaron los dos primeros intentos desestabilizadores, de la misma forma fracasará el tercero de ellos, sin importar el estatus o la trayectoria de sus integrantes.

Es posible que esta lectura sea correcta. Sin embargo, es útil intentar otro tipo de análisis, aunque sea sólo por el afán de explorar otras formas de ver la dinámica de la izquierda salvadoreña. Para comenzar, hay que preguntarse por el carácter del FDR, es decir, por su identidad como proyecto político. Se trata, sin duda, de un partido de izquierda, pero no de una izquierda que adversa los principios fundamentales del FMLN. Para el FDR, lo que está en cuestión no es el proyecto efemelenista, sino la cúpula que lo dirige; es el rechazo a esa cúpula lo que ba llevado a cuadros importantes del partido a integrarse a un nuevo proyecto político. Esta situación tiene aspectos novedosos, si se la compara con la que llevó a la formación, por ejemplo, del PD. Este último puso en tela de juicio el proyecto efemelenista; de becho, quiso ser un proyecto destinado a reemplazarlo, lo cual explica en parte su fracaso. El FDR viene a ser una especie de intento por recuperar lo mejor del FMLN — por lo menos en la intención de quienes le quieren dar vida-, y que no puede expresarse por el férreo control ejercido sobre los militantes $y$ mandos medios por la actual cúpula del partido. No es gratuito que la nueva formación política lleve por nombre "Frente Democrático Revolucionario": pretende recuperar con ese nombre $y$ las siglas respectivas el simbolismo de la izquierda democrática que, en los años ochenta, se asoció estratégicamente al FMLN, porque compartía y babia becho suyos los ideales del ejército guerrillero. En aquellos años, FDR-FMLN significaban compromiso, sacrificio y deseos incontenibles de construir un nuevo proyecto de nación para El Salvador. Esto es lo que quiere poner en juego, en una época distinta, el FDR; quiere usar esa berencia simbólica para desafiar a la cúpula actual del FMLN. 
En el FDR, pues, el asunto es bastante claro: el problema en el FMLN es la cúpula; es su intransigencia, su intolerancia y su ansia de control lo que ba obligado a muchos de sus cuadros - que no ban renegado de sus ideales democrático-revolucionarios-, a buscar refugio en un proyecto en el cual los intereses de la cúpula no sean una camisa de fuerza para los militantes. Desde el FMLN, las cosas también son bastante claras: al FDR no sólo han ido a parar los ambiciosos y renegados, los que le hacen el juego a la derecha, sino que se trata de un proyecto político condenado a desaparecer.

Es claro que la lectura del FMLN es simplista y cómoda. Más aún, es peligrosa para sus perspectivas electorales, porque pierde de vista la posibilidad de que, al contrario de lo que sucedió con el $P D$ y el Movimiento Renovador, el FDR si logre arrebatarle un número significativo de votos en las próximas o en las siguientes elecciones. Obviamente, aceptar esta eventualidad supone aceptar que el malestar en torno a la forma cómo es conducido el partidoesgrimidos por muchos de los que se han dejado el FMLN y se ban integrado al FDR - puede haber llegado a la militancia, bases y simpatizantes del partido.

No se ven señales de que la cúpula efemelenista esté dispuesta a hacerse cargo, ni siquiera por mera prudencia, de una situación como la apuntada. Por tanto, no se ve cómo el FMLN pueda prepararse con realismo no sólo para ceder parte de su caudal electoral a otro partido de izquierda, sino para seguir siendo un actor político decisivo con un voto de izquierda dividido. Con un panorama como el esbozado, las perspectivas políticas de la izquierda - la que se aglutina en torno al FMLN y la que se sitúa fuera de él- son francamente sombrias. Son también sombrias las perspectivas para la sociedad salvadoreña, para la cual no se avizora otra cosa en horizonte más que un dominio continuado de la derecha representada por ARENA. Sin un proyecto politico alternativo de izquierda, viable, realista, creíble; con una izquierda fragmentada $y$ en lucha consigo misma; con un FMLN reacio a revisar, desde su cúpula, sus debilidades ideológicas y políticas; con una militancia efemelenista confundida $y$, muchas veces, agresiva... Con todo eso, es difícil que emerja en El Salvador una opción política que en verdad ofrezca algo mejor y distinto a lo ofrecido por ARENA. 